\title{
Multinuclear NMR of Calcium Fructoborate Complex - Structure, Stability, and Quantitation in the Presence of Other Ingredients, Excipients or Adulterants
}

\author{
John C. Edwards ${ }^{1}$, John M. Hunter ${ }^{2} \&$ Boris V. Nemzer ${ }^{2,3}$ \\ ${ }^{1}$ Process NMR Associates, LLC, Danbury, CT, USA \\ ${ }^{2}$ VDF FutureCeuticals, Inc., Momence, IL, USA \\ ${ }^{3}$ Department of Food Science and Human Nutrition, University Illinois at Urbana Champaign, Urbana, IL, USA \\ Correspondence: Boris Nemzer, FutureCeuticals, Inc., 2692 N. State Rt. 1-17, Momence, IL, 60954USA, Tel: \\ 1-812-507-1427. E-mail: bnemzer@futureceuticals.com
}

Received: March 2, 2014 Accepted: May 13, 2014 Online Published: May 16, 2014

doi:10.5539/jfr.v3n3p115 URL: http://dx.doi.org/10.5539/jfr.v3n3p115

\begin{abstract}
FruiteX-B ${ }^{\circledR}$ - calcium fructoborate (FrxB) plant mineral complex was investigated in this study. Although calcium fructoborate is naturally-occurring and found in commonly ingested fruits and vegetables, the commercially produced FrxB calcium fructoborate complex is formed by a proprietary reaction of boric acid with fructose and calcium carbonate. Liquid and solid-state ${ }^{13} \mathrm{C}$ and ${ }^{11} \mathrm{~B}$ NMR were utilized in order to establish a baseline standard of FrxB for product quality purposes, to establish a reliable methodology to positively identify and quantify amounts of FrxB present in tablets and capsules, liquids and powdered blends wherein the FrxB may have been mixed with other ingredients, excipients, or adulterants such as maltodextrin or magnesium stearate, and to establish a robust and reliable testing method for the identification and quantification of the mono- and the di-complexes of calcium fructoborate as well as any free borate and/or free fructose that may be present. The molar ratio of the various components of calcium fructoborate was studied by ${ }^{11} \mathrm{~B}$ and ${ }^{13} \mathrm{C}$ NMR in order to establish the relative amounts of free borate, free fructose, and mono-ester/di-ester complex present in the material. A quantitative ${ }^{11} \mathrm{~B}$ NMR method was developed to enable quantification of the amount of FrxB present in products wherein it had been tableted or encapsulated in combination with other dietary supplement ingredients, or excipients such as magnesium stearate or maltodextrin. A quantitative ${ }^{13} \mathrm{C}$ NMR method was developed to quantify free fructose content in the complex. Finally, an NMR based product stability study was performed to monitor molecular level stability of the complex at temperatures ranging from $35-70{ }^{\circ} \mathrm{C}$ with exposures lasting from 2-18 hours.
\end{abstract}

Keywords: fructoborate, NMR, fructose, ${ }^{11} \mathrm{~B}$ NMR, ${ }^{13} \mathrm{C}$ NMR, ${ }^{1} \mathrm{H}$ NMR, solid-state, liquid-state, qNMR

\section{Introduction}

The element boron is essential for all plant and animal life. Plants were first found to contain boron (B) in 1857. It is currently well recognized that boron, at about $0.5 \mathrm{ppm}$, is an essential element for normal plant growth. Numerous studies have reported the nutritional benefits of boron-containing compounds (Nielsen, 2008; Meacham et al., 2010; Hunt, 2012; Dinca \& Scorei, 2013), metabolic functions (Bakirdere et al., 2010; Neilsen et al., 2011) and potential therapeutic applications (Scorei \& Popa, 2010; Dembitsky et al., 2011). Although, certain inorganic borates, e.g., boric acid or sodium borate, have been used for dietary supplementation, animals typically ingest boron-containing compounds in the form boro-carbohydrates found in the plants that they eat. Interestingly, boron is capable of complexation with many biological compounds. Polysaccharides, -alcohols, pyranose and furanose sugars or their derivatives, and organic acids readily form complexes with boric acid. Boric acid forms esters and complexes with a wide variety of mono-, di-, and polyhydroxy compounds (Woods, 1996; Köse et al., 2010; Köse et al., 2014). Some of the most stable esters of boric acid are complexes wherein boric acid acts as a bridge between two carbohydrate molecules, e.g. fructose-boron-fructose. For better understanding of the primary functions of these important boro-carbohydrates in both plants and animals, more effective methodological developments are required, especially for the study of their detailed chemical distribution, the molecular receptor site, transportation, absorption, and the exchange of these borates and boron 
within tissues. Previous examination of boron complexation in plants and plant extracts by ${ }^{11} \mathrm{~B}$ NMR demonstrated that the majority of boron is associated with diester complexes of diols and hydroxycarboxylic acids in radish and apple respectively (Matsunaga \& Nagata, 1995) wherein the authors made the conclusion that fructose is the most significant boron complexing molecule. Later these hypotheses were verified (Brown \& Shelp, 1997; Hu, Penn, Lebrilla, \& Brown, 1997) after successful isolation and full characterization of soluble boron complexes from higher plants.

The interaction between calcium (Ca) and boron (B) has previously been observed in plants, bacteria, animals, and humans and was reported in a number of papers (Yamanouchi, 1973; Bonilla et al., 1995; Brown et al., 2002); however, the specific nature of the $\mathrm{Ca} / \mathrm{B}$ interaction is still under experimental investigation (Bolanos et. al., 2004). Calcium fructoborate (CF) is most commonly found in fresh fruits and vegetables. It is exclusively manufactured under US patent 5,962,049 (Miljkovic, 1999, as well as other foreign patents and patent applications) and is sold as a dietary supplement by VDF FutureCeuticals, Inc (Momence, IL, USA) under the commercial name FruiteX-B ${ }^{\circledR}$ (FrxB). The characterization of this complex has been reported previously (Rotaru et. al., 2010) using thermal analysis, X-rays diffraction, ICP-MS, Raman spectrometry techniques. The biological and biochemical action of $\mathrm{CF}$ has been studied and found that it has a chemical structure similar to that of natural boro-carbohydrates found in edible plants (Brown, 1997; Scorei, Cimpoiasu, \& Iordachescu, 2005; Curotto, Deiz, \& Bara, 2008; Scorei \& Popa, 2010; Scorei \& Rotaru, 2011)

The objective of this study was to investigate the molecular composition of FrxB, to provide the relative distribution of boron in free and chelated forms, the stability of FrxB at different temperatures, and to identify FrxB alone, and when in adulterated forms of the material used as dietary supplements for human nutrition (Dinca \& Scorei, 2013, Reyes-Izquierdo et al., 2012), using liquid- and solid-state ${ }^{11} \mathrm{~B}$ and ${ }^{13} \mathrm{C}$ NMR.

\section{Materials and Method}

\subsection{Materials}

FruiteX- $\mathrm{B}^{\circledR}$ calcium fructoborate (FrxB) is a patented plant mineral complex that is marketed as a nutritional supplement having potential health benefits for support of bone, joint and cardiovascular health. This calcium fructoborate complex is formed by a proprietary reaction of boric acid with fructose and calcium carbonate. FrxB was manufactured and provided by VDF FutureCeuticals, Inc. (Momence IL, USA).

All NMR analysis was performed in $\mathrm{D}_{2} \mathrm{O}$ or $\mathrm{H}_{2} \mathrm{O} / \mathrm{D}_{2} \mathrm{O} . \mathrm{D}_{2} \mathrm{O}(99.9 \% \mathrm{D})$ was obtained from Cambridge Isotopes Laboratories, Tewksbury MA, USA.

\subsection{NMR Spectroscopy}

Liquid-state ${ }^{11} \mathrm{~B},{ }^{13} \mathrm{C}$, and ${ }^{1} \mathrm{H}$ NMR was performed on a Varian Mercury 300MVX NMR spectrometer equipped with a $5 \mathrm{~mm}$ Varian ATB Probe at resonance frequencies of $96.14 \mathrm{MHz}\left({ }^{11} \mathrm{~B}\right), 75.36 \mathrm{MHz}\left({ }^{13} \mathrm{C}\right)$ and $299.67 \mathrm{MHz}$ $\left({ }^{1} \mathrm{H}\right)$, respectively. ${ }^{11} \mathrm{~B}$ spectra were acquired with a 45 degree tip angle pulse width, a relaxation delay of 0.2 seconds, an acquisition time of $80 \mathrm{~ms}$ with $8 \mathrm{~K}$ points acquired with a spectral width of $100 \mathrm{kHz}$, and 1024 pulses were averaged. The data was zero filled to $65 \mathrm{~K}$ points. The ${ }^{13} \mathrm{C}$ NMR was acquired with a 30 degree tip angle pulse width, a relaxation delay of 5 seconds, 0.96 second acquisition time, with $24 \mathrm{~K}$ points acquired with a spectral width of $25 \mathrm{kHz}$, and 10-12,000 pulses were averaged. The data was zero filled to $131 \mathrm{~K}$ points. The ${ }^{1} \mathrm{H}$ NMR spectra were obtained with a 30 degree pulse angle, a relaxation delay of 2 seconds, a 4.448 second acquisition time, with $32 \mathrm{~K}$ points acquired over a spectral width of $7.2 \mathrm{kHz}$, and 128 pulses were averaged. The data was zero-filled to $131 \mathrm{~K}$ points. The data was acquired in a quantitative manner with inverse gated decoupling of protons during the acquisition of the ${ }^{11} \mathrm{~B}$ and ${ }^{13} \mathrm{C}$ experiments. All samples were dissolved in $\mathrm{D}_{2} \mathrm{O}$ (Cambridge Isotope Laboratories). No $\mathrm{pH}$ adjustments were performed on the samples after dissolution.

Solid-State ${ }^{13} \mathrm{C}(50.30 \mathrm{MHz}),{ }^{11} \mathrm{~B}(64.17 \mathrm{MHz})$ NMR spectra were obtained on a Varian UnityPlus-200 NMR spectrometer equipped with a Doty Scientific $7 \mathrm{~mm}$ Supersonic CP-MAS probe. Magic angle spinning (MAS) speeds of around $6 \mathrm{kHz}$ were employed. The ${ }^{13} \mathrm{C}$ NMR data was acquired using cross polarization which prepares the magnetization on the protons initially and then transfers the spin locked magnetization to the ${ }^{13} \mathrm{C}$ nuclei. The advantage of this experiment is the fact that it is performed at the spin-lattice relaxation rate $\left(\mathrm{T}_{1}\right)$ of protons in the sample which is considerably shorter than the $\mathrm{T}_{1}$ of ${ }^{13} \mathrm{C}$ nuclei in the same sample. Thus, one obtains a significant enhancement of the ${ }^{13} \mathrm{C}$ signal from the polarization transfer and can pulse at a shorter pulse-repetition rate. The ${ }^{13} \mathrm{C}$ CP-MAS experiment on calcium fructoborate complex was performed with a $1 \mathrm{~ms}$ variable amplitude contact time, an 8 second relaxation rate, and an acquisition time of $25.6 \mathrm{~ms}$, with $1 \mathrm{~K}$ points being acquired over a spectral with of $40 \mathrm{kHz}$, and 4096 pulses were averaged. The exceptions to these acquisition parameters were those used for pure crystalline fructose. The ${ }^{11} \mathrm{~B}$ NMR spectra were acquired with 
MAS and with the sample remaining static in the NMR probe. The experiments were acquired with a central transition selective pulse width, a 0.2 second relaxation time, with $1 \mathrm{~K}$ points being acquired in an acquisition time of $10.2 \mathrm{~ms}$, and with a spectral width of $100 \mathrm{kHz}$.

Samples were observed directly after they were received, after they had been thermally treated in a Duratech TCON dry bath system (capable of holding temperatures to $+/-0.1{ }^{\circ} \mathrm{C}$ ), or as calibration standards which were made by mixing accurately weighed samples of FrxB with magnesium stearate or maltodextrin. Samples for solid-state NMR were weighed to the nearest $0.1 \mathrm{mg}$ on a Sartorius GD-503-NTEP microbalance after they were packed into the MAS rotor.

\section{Results and Discussion}

\subsection{Structure of the Calcium Fructoborate Complex}

\subsection{1 ${ }^{1} \mathrm{H}$ NMR}

Figure 1 shows the spectrum of pure D-fructose compared to the spectrum of the FruiteX- ${ }^{\circledR}$ calcium fructoborate complex (FrxB). Peaks that can be assigned to free fructose are observed as well as the mono-ester/di-ester complex in the FrxB sample but, because the overall spectrum is complicated, no assignments have been made in the ${ }^{1} \mathrm{H}$ NMR spectrum due to its complexity. The ${ }^{1} \mathrm{H}$ NMR spectrum can be used to quantify the presence of FrxB in combination with excipients such as maltodextrin, other dietary ingredients, and potential adulterants such as boric acid or free fructose.
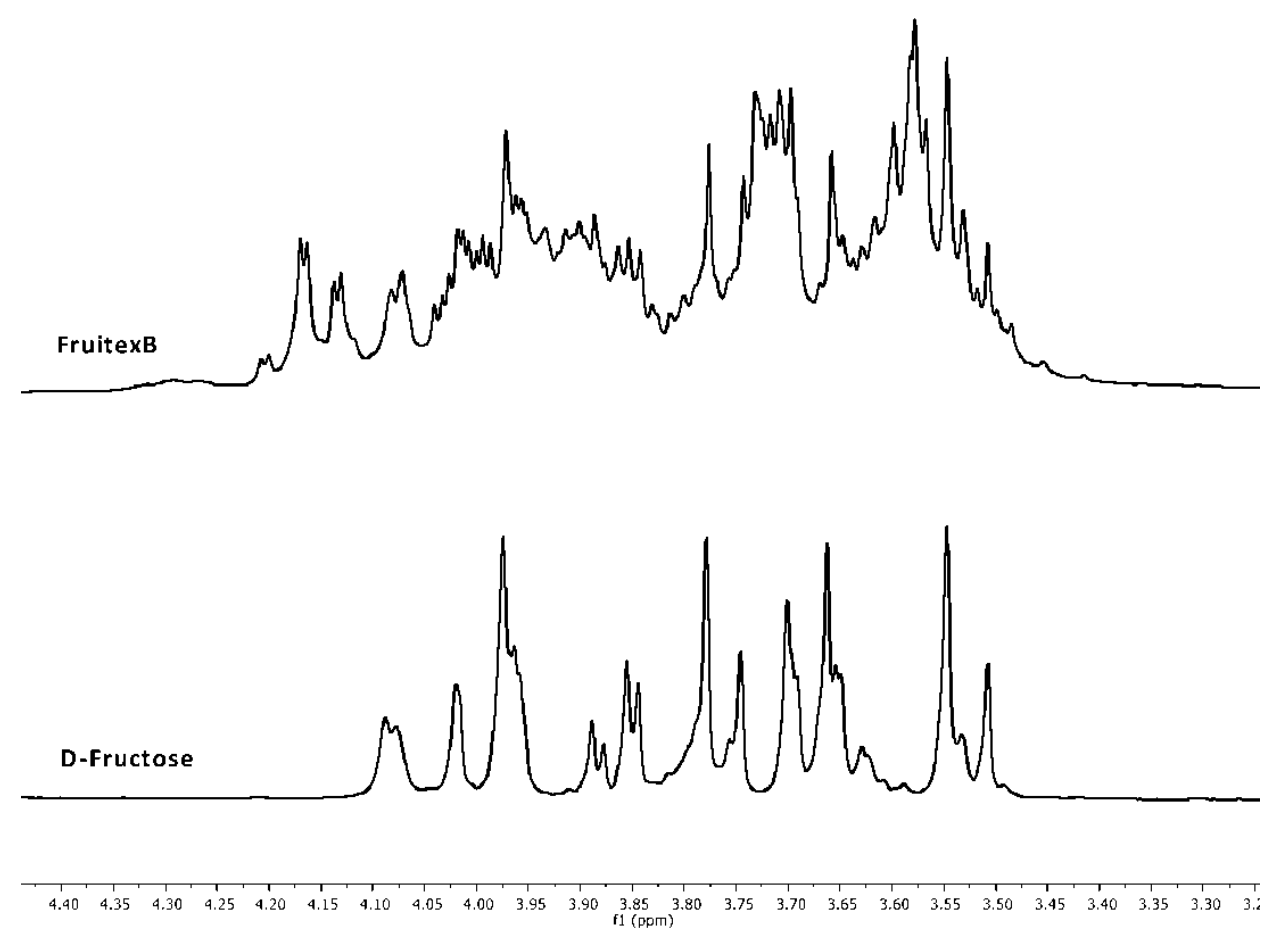

Figure 1. ${ }^{1} \mathrm{H}$ NMR spectral comparison of D-fructose and FrxB

\subsection{2 ${ }^{13} \mathrm{C}$ NMR}

As a starting point for understanding the FrxB composition we fully characterized D-fructose by ${ }^{13} \mathrm{C}$ NMR. There is a lot of NMR information available on fructose in the literature to aid in the assignment (Consonni \& Cagliani, 2008, Barclay, Ginic-Markovic, Johnston, Cooper, \& Petrovsky, 2012, and Mazzoni, Bradesi, Tomi \& Casanova, 1997). Figure 2 shows the assignment of the ${ }^{13} \mathrm{C}$ NMR spectrum of D-Fructose which has a number of tautomers present in exchange when dissolved in $\mathrm{D}_{2} \mathrm{O}$. From the D-fructose anomeric carbon region (C-2), that lies between 98 and $105 \mathrm{ppm}$, the assigned tautomer peaks were integrated and the mole\% of each tautomer was calculated.

The tautomers identified were: $\beta$-fructopyranose $(\beta-\mathrm{FP}), \beta$-fructofuranose. $(\beta$-FF), and $\alpha$-fructofuranose $(\alpha-\mathrm{FF})$ 
which are present at $71.1 \%, 22.4 \%$ and $6.5 \%$, respectively.

The FrxB calcium fructoborate complex is formed upon complexation of fructose with $\mathrm{CaCO}_{3}$ and boric acid. This complex has been studied previously (Wagner et al., 2008; Rotaru et al., 2010) with FT-IR and Raman spectroscopies. In this study the ${ }^{13} \mathrm{C}$ NMR spectra of 3 lots of FrxB are shown in Figure 3 with the full assignment of the anomeric peaks and a comparison spectrum of pure fructose. Unreacted fructose (free fructose) is observed in the FrxB complex mixture and a 3-7 ppm downfield shift of the fructose resonances is observed for the carbons coordinated to borate.

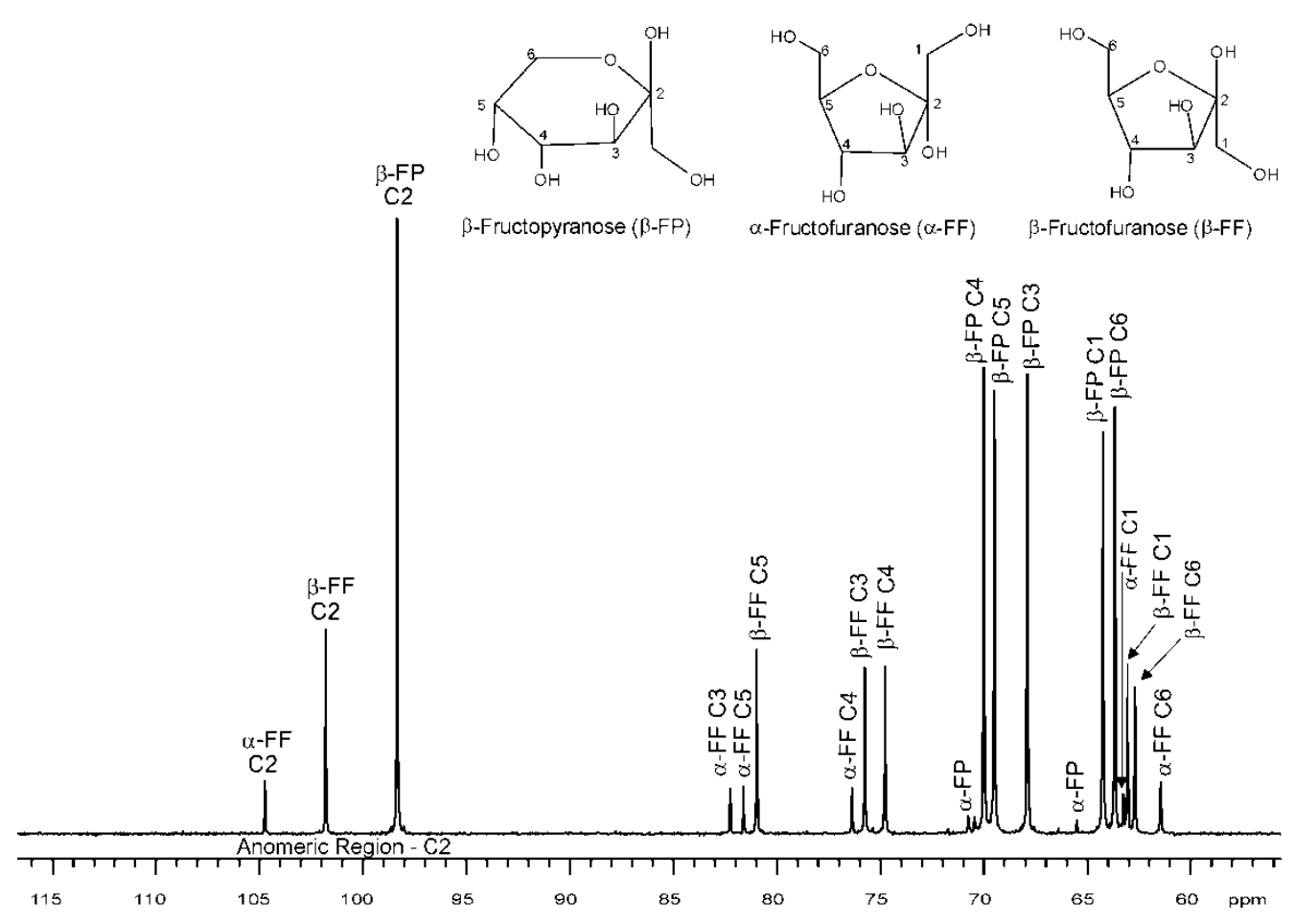

Figure 2. Assignment of ${ }^{13} \mathrm{C}$ NMR spectrum of D-fructose in $\mathrm{D}_{2} \mathrm{O}$

The change of relative signal intensity in the regions of the spectrum that are associated with furanose tautomers indicates that the tautomer distribution of the complex strongly favors the reaction of borate with the fructofuranose (FF) form. As the FF form is formed in the equilibrium isomerization with fructopyranose (FP) it preferentially reacts with borate faster than the FP form leading to a predominance of FF in the FrxB. The 74-83 ppm region of the fructose spectrum contains peaks from exclusively FF C-3, C-4, C-5 carbons. In the FrxB complex these same carbons are found with $2-6 \mathrm{ppm}$ downfield shifts to produce multiple-component peaks observed at $77.5,84$, and $86 \mathrm{ppm}$, respectively. The integrated signal intensity of these boron complexed peaks was considerably increased when compared to pure fructose, thus indicating a preference for borate coordination to the FF form. In the anomeric region of the spectrum $(98-112 \mathrm{ppm})$ it was possible to assign and quantify the relative amounts of the various fructose tautomers that were present in the FrxB complex. The predominant form of fructoborate was the $\alpha$-FF form present as a multiple component peak at $111 \mathrm{ppm}$, the $\beta$-FF form was the second highest in concentration with a multiple component peak observed at $104 \mathrm{ppm}$ and finally the $\alpha / \beta-\mathrm{FP}$ form was the lowest concentration with a multiple component peak at $101 \mathrm{ppm}$. Table 1 shows the relative mole $\%$ of the fructose forms found in the FrxB complex based on the ${ }^{13} \mathrm{C}$ quantitative NMR analysis. The fact that the FrxB complex peaks were multi-component in all cases leads to the conclusion that the borate reacts with multiple hydroxyls with $\mathrm{OH}$ condensation reactions occurring predominantly on the $\mathrm{C}-1 / \mathrm{C}-2$ as well as on the $\mathrm{C}-3 / \mathrm{C}-4$ of the FF forms. It is expected from the mole ratios utilized during the synthesis of the FrxB complex that the complex was predominantly the di-ester form $\mathrm{BL}_{2}^{-}$form (one borate coordinated to two fructose molecules) with the minor constituent being the monoester form $\left(\mathrm{BL}^{-}\right)$, as well as some free/unreacted borate. This observation was confirmed in the ${ }^{11} \mathrm{~B}$ NMR results to be discussed later. There are a large number of different combinations of borate condensation reactions with different fructose forms and $\mathrm{OH}$ positions which 
leads to multicomponent ${ }^{13} \mathrm{C}$ NMR peak regions.

The ${ }^{13} \mathrm{C}$ NMR of the anomeric (C-2) region was also utilized to determine the consistency of the fructoborate complex formation from one batch to the next. Figure 4 shows a stacked plot of several lots of FrxB compared to pure D-fructose.

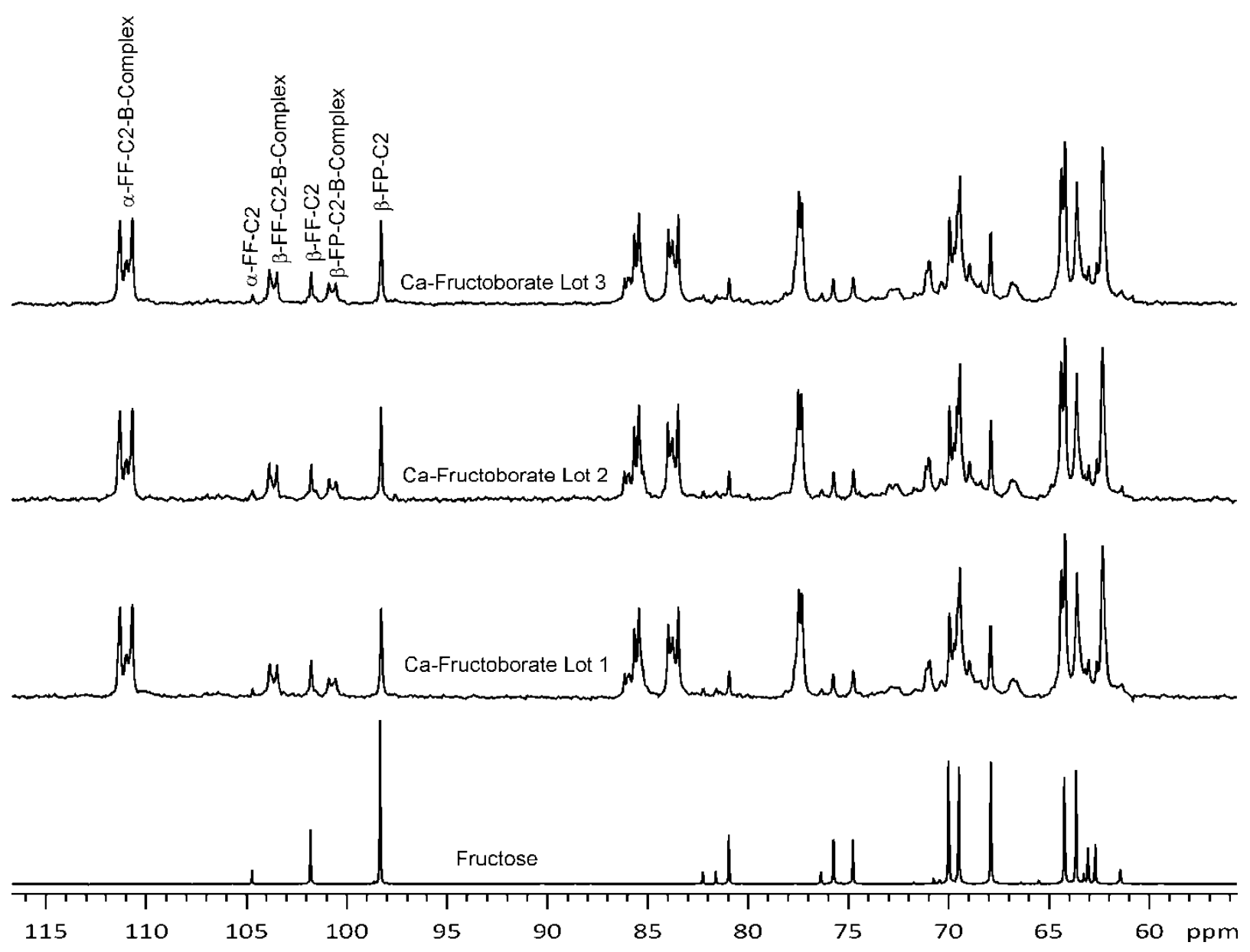

Figure $3 .{ }^{13} \mathrm{C}$ NMR of lot-to-lot consistency of FrxB - free fructose is observed in final product complex

Table 1 shows the relative concentrations of the observed free fructose tautomers and the FrxB fructose tautomer forms. Note that the preference is highly favored toward the FF form of the FrxB complex compared to the D-fructose which favors the FP form.

Table 1. Relative molar concentrations found in different lots of calcium fructoborate complex

\begin{tabular}{llll}
\hline Fructose Tautomer & Lot 1 (mole\%) & Lot 2 (mole\%) & Lot 3 (mole\%) \\
\hline$\beta$-FP (Free Fructose) & 15.5 & 13.9 & 15.7 \\
$\beta$-FF (Free Fructose) & 7.9 & 7.1 & 8.5 \\
$\alpha$-FF (Free Fructose) & 1.6 & 2.0 & 1.8 \\
$\alpha$-FF-B-Complex & 48.3 & 50.5 & 47.6 \\
$\beta$-FF-B-Complex & 17.0 & 16.3 & 16.3 \\
$\beta$-FP-B-Complex & 9.6 & 10.2 & 10.0 \\
\hline
\end{tabular}

Another important use of the ${ }^{13} \mathrm{C}$ NMR analysis is to determine the temperature and storage stability of the 
powder form of the FrxB complex. Temperature stability experiments were carried out on the powder form of the complex by exposing samples to a number of temperatures $\left(35,50\right.$ and $\left.70{ }^{\circ} \mathrm{C}\right)$ for a series of times $(2,4,6$, and 18 hours). Figure 4 shows the ${ }^{13} \mathrm{C}$ NMR spectra of a single lot of FrxB exposed to these different temperatures for between 2 and 18 hours. The variance in the relative amounts of the calcium fructoborate and free fructose components was found to be within the margin of error of the ${ }^{13} \mathrm{C}$ integration $(\sim 1-2 \%)$, indicating that at the temperatures of the stability test did not cause a degradation or change in the FrxB complex chemistry.

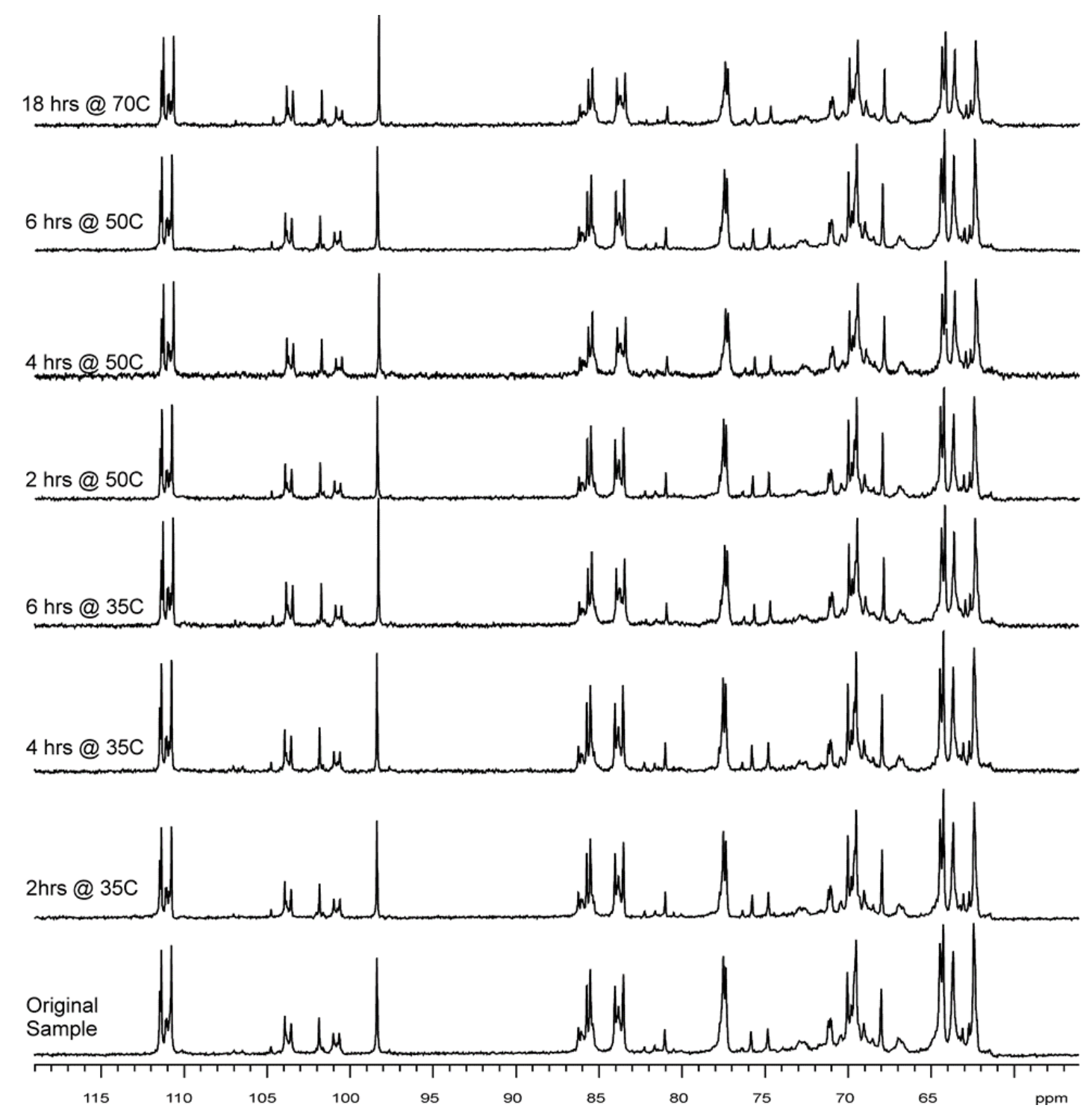

Figure $4 .{ }^{13} \mathrm{C}$ NMR of a single lot of FrxB complex exposed to temperatures of 35,50 , and $70{ }^{\circ} \mathrm{C}$ for time periods between 2-8 hours

Solid-state ${ }^{13} \mathrm{C}$ NMR was also routinely obtained on FrxB samples in order to gain a perspective on differences that might occur in the chemistry of the solid powder sample and that of the dissolved complex where equilibrium chemistry may modify the distribution of complex components. Figure 5 shows the solid-state ${ }^{13} \mathrm{C}$ CP-MAS NMR spectra obtained on D-fructose and also on a typical lot of FrxB obtained under two different experimental conditions. It was found that the highly crystalline single tautomer form of the solid D-fructose sample caused the spin-lattice relaxation time $\left(T_{1}\right)$ to be on the order of 240 seconds. This exceedingly long relaxation time means that a quantitative spectrum of D-fructose would require a pulse repetition rate of 1200 seconds. It was decided to obtain the solid-state ${ }^{13} \mathrm{C}$ CP-MAS spectrum on the FrxB complex under two pulse repetition conditions to determine if narrow signals from crystalline D-Fructose could be observed in the FrxB. 
From the spectrum obtained with a $300 \mathrm{sec}$ repetition rate it can be seen that no narrow crystalline peaks were observed, indicating that the free fructose observed in the liquid-state ${ }^{13} \mathrm{C}$ NMR experiments is intimately mixed with the fructoborate complex and does not retain any of its original crystalline structure.

Solid-state ${ }^{13} \mathrm{C}$ NMR was also utilized to investigate the thermal stability of the carbon chemistry present in the powder sample of FrxB after exposure to temperatures of 50 and $70{ }^{\circ} \mathrm{C}$ for $2-18$ hours. Figure 6 shows the spectra obtained on the temperature stability samples which show no observable differences in the carbon chemistry distribution indicating that the powder form of the FrxB is thermally stable in that temperature exposure range.

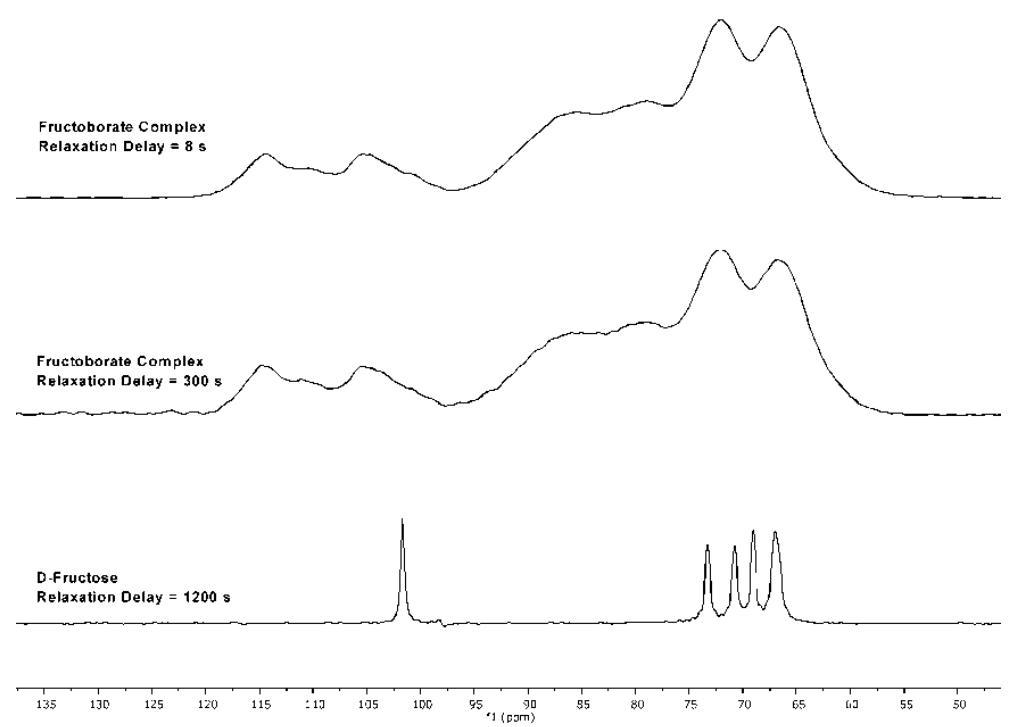

Figure 5. Solid-state ${ }^{13} \mathrm{C}$ NMR spectra obtained on D-fructose (relaxation delay 1200 seconds), and also on a FrxB sample obtained with two different relaxation delays to allow observation of crystalline D-fructose in the complex powder

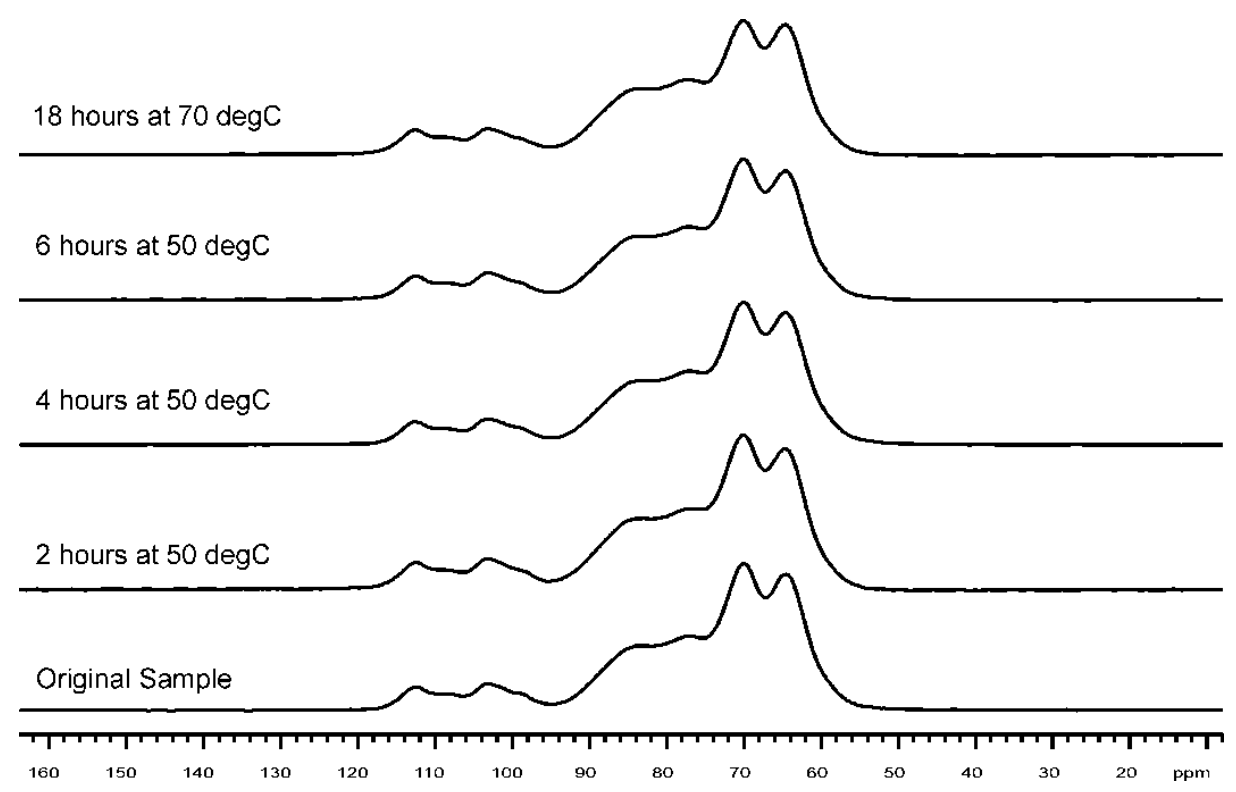

Figure 6. Solid-state ${ }^{13} \mathrm{C}$ NMR of an FrxB sample exposed to temperatures of 50 and $70{ }^{\circ} \mathrm{C}$ for 2-18 hours 


\subsection{3 ${ }^{11} \mathrm{~B}$ NMR}

Liquid-state ${ }^{11} \mathrm{~B}$ NMR has often been utilized in the study of biomedical applications of boron (Bendel, 2005). In this study liquid-state ${ }^{11} \mathrm{~B}$ NMR was obtained in order to observe the FrxB complex from the perspective of the boron chemistry. Previous research has identified that three basic types of boron-containing molecule are observed in aqueous solutions of FrxB. Free boric acid is observed at $0 \mathrm{ppm}$, the di-ester complex $\left(\mathrm{BL}_{2}{ }^{-}\right)$is observed at $-9 \mathrm{ppm}$, and the mono-ester $\left(\mathrm{BL}^{-}\right)$complex is observed at $-13 \mathrm{ppm}$ (Makkee, Keibook, \& van Bekkum, 1985, Reyes-Izquierdo et al., 2012; Smith, Owens, Bowman, \& Todd, 1998). The relative molar concentrations of these three types of boron-containing molecule were found to be approximately $5 \%, 85 \%$, and $10 \%$, respectively. Figure 7 shows the liquid-state ${ }^{11} \mathrm{~B}$ NMR spectra of boric acid and 3 production lots of FrxB.

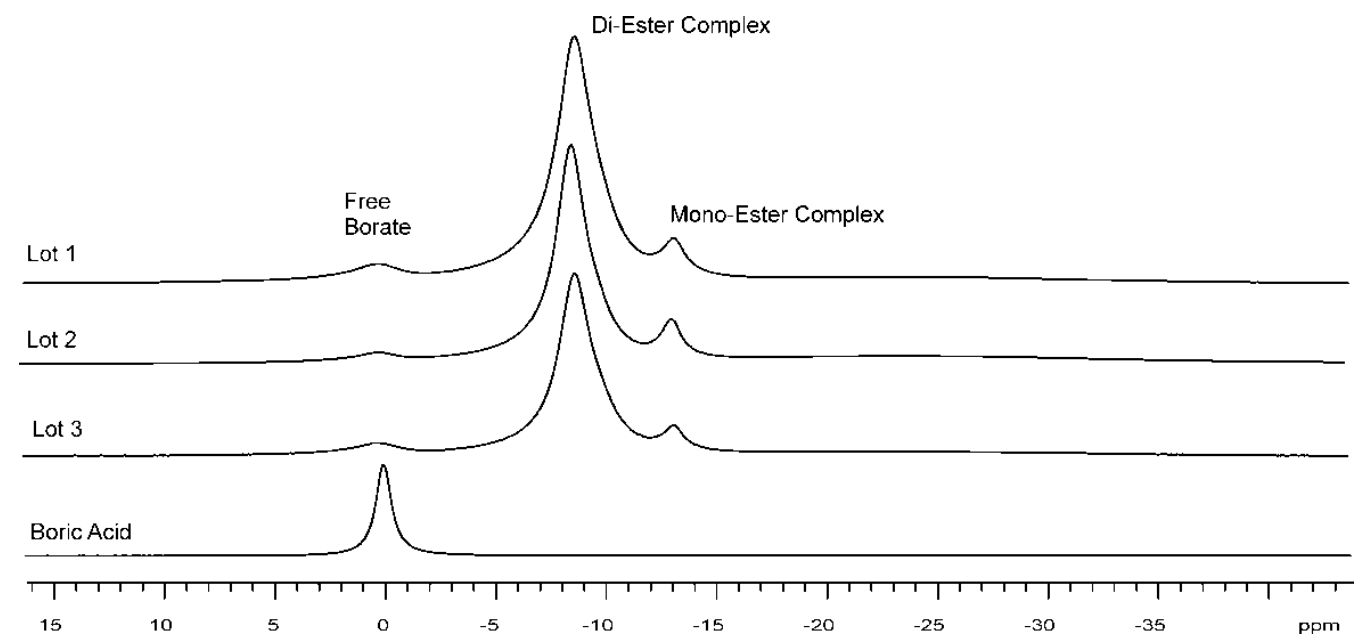

Figure 7. Liquid-state ${ }^{11} \mathrm{~B}$ NMR of boric acid and three lots of FrxB

Solid-state ${ }^{11} \mathrm{~B}$ NMR was also obtained on FrxB samples and Figure 8 shows static NMR powder line-shape spectra for boric acid and three representative FrxB lots. Both static and magic angle spinning date can be used to obtain comparative spectral response to prove lot-to-lot consistency.

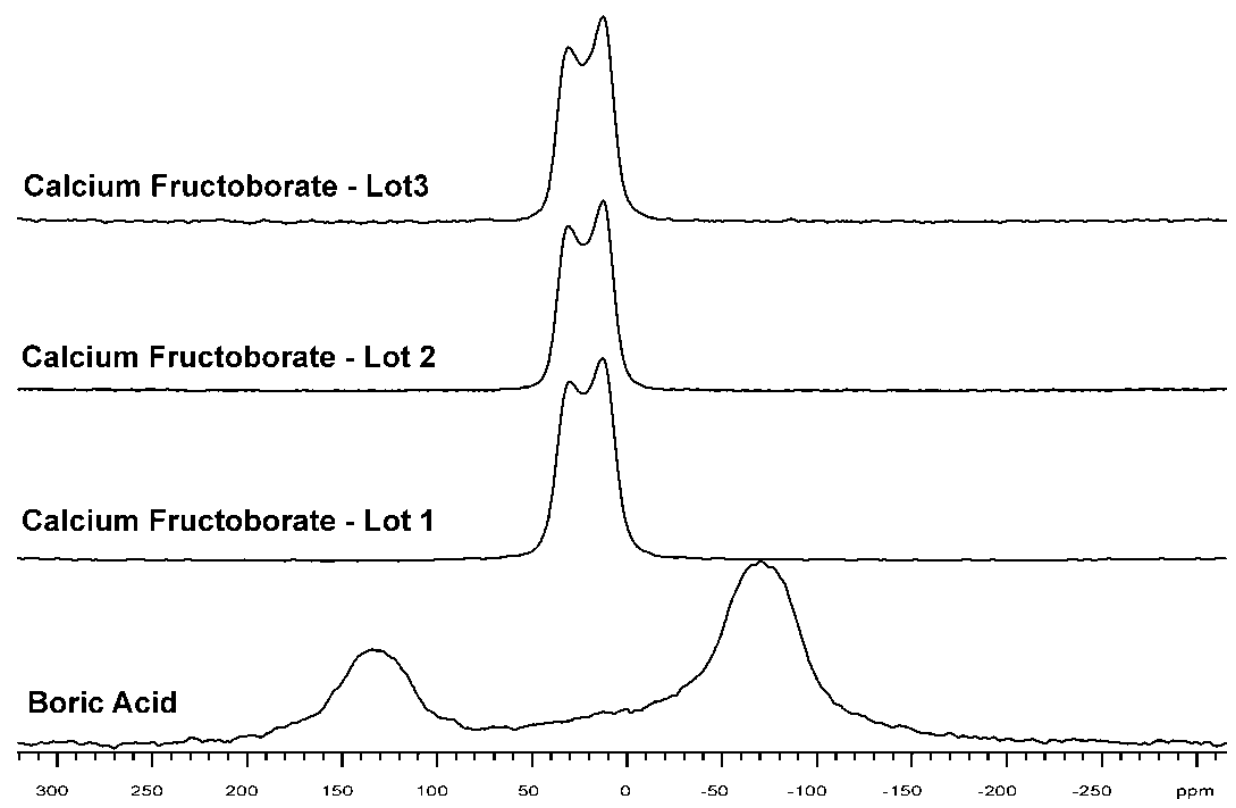

Figure 8. Solid-state ${ }^{11}$ B NMR Static lineshapes obtained on boric acid and 3 production lots of FrxB 
The solid-state spectra demonstrate that any free boric acid or borate that is present in the powder sample is intimately integrated into the mixture and no crystalline domains of these species exist in FrxB as the broad signals expected from crystalline borate/boric acid are not observed. ${ }^{11} \mathrm{~B}$ is a quadrupolar nucleus with nuclear spin 3/2 which means that it does not yield the symmetric NMR peaks typical of spin $1 / 2$ nuclei such as ${ }^{1} \mathrm{H}$ and ${ }^{13} \mathrm{C}$. We did not attempt to fit the quadrupolar line-shape in order to determine if there were overlapping signals from the three different boron-containing molecule types in FrxB. However the consistency of the line-shape (shape and width) was utilized in order to determine if changes (chemical of physical) were occurring around the boron center.

Changes that are observed in quadrupolar line-shapes indicate differences in symmetry at the boron nucleus in a given molecule. These changes in symmetry are caused by changes in molecular coordination chemistry, crystal structure, amorphous structure or by the presence of varying amounts of water of crystallization in the FrxB powder (Freude, 2000).

The liquid-state (Figure 9) and solid-state ${ }^{11} \mathrm{~B}$ NMR experiments were used to determine the FrxB temperature stability on the same series of FrxB samples investigated previously by ${ }^{13} \mathrm{C}$ NMR. The samples were heat-treated at 35,50 and $70{ }^{\circ} \mathrm{C}$ for $2-18$ hours. No observable changes in relative amounts of the three boron-containing molecule types are observed in the liquid-state NMR. The quadrupole lineshape observed in the solid-state ${ }^{11} \mathrm{~B}$ NMR showed a constant quadrupole coupling value across all temperatures and times of exposure indicating that no change in sample chemistry had occurred under the temperature conditions of the test. Based on the ${ }^{11} \mathrm{~B}$ and ${ }^{13} \mathrm{C}$ NMR results Figure 10 shows the prevalent $\mathrm{BL}^{-}$and $\mathrm{BL}_{2}^{-}$fructoborate complexes present in the FrxB product.

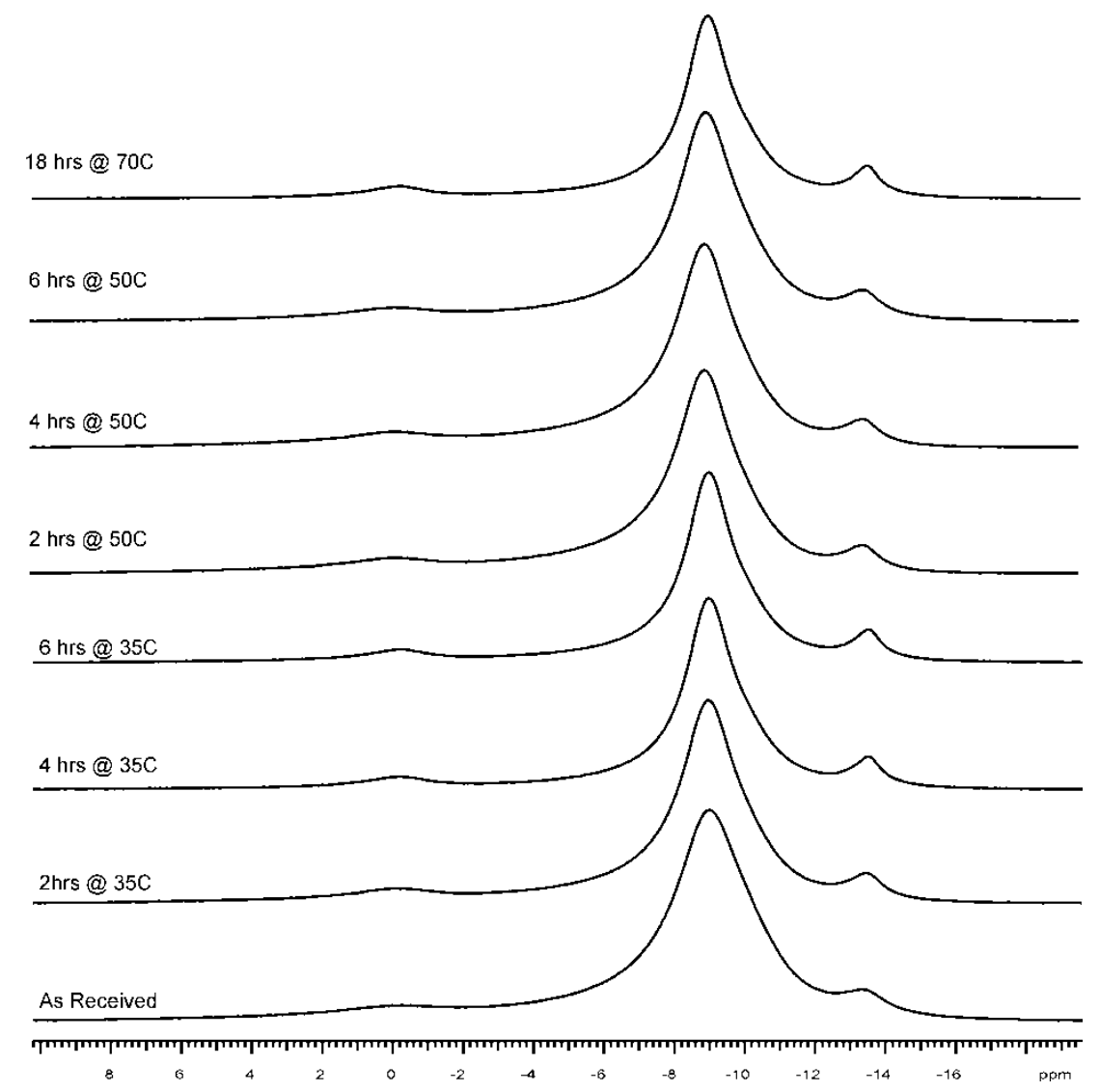

Figure 9. Liquid-state ${ }^{11} \mathrm{~B}$ NMR spectra of temperature stability study sample of FrxB exposed to temperatures of 35,50 and $70{ }^{\circ} \mathrm{C}$ for $2-18$ hours

\subsection{Quantitative Analysis of FrxB Content in Tablet or Adulterated Samples}

The spectroscopic tools of liquid-state and solid-state ${ }^{1} \mathrm{H},{ }^{13} \mathrm{C}$, and ${ }^{11} \mathrm{~B}$ NMR were utilized to investigate the 
possibility of utilizing quantitative NMR (qNMR) (Pieters \& Vlietinck, 1989; Pauli, Gödecke, Jaki, \& Lankin, 2012; Caytan et al., 2007) to positively identify and quantify FrxB present in tablets and capsules where the FrxB has been intimately mixed with excipients such as maltodextrin or magnesium stearate. Sample mixtures were made by mixing $5,10,20$, and $50 \mathrm{wt} \%$ FrxB with either maltodextrin or magnesium stearate.

The first approach was to utilize liquid-state ${ }^{1} \mathrm{H},{ }^{13} \mathrm{C}$, and ${ }^{11} \mathrm{~B}$ to create calibrations that could be used to obtain $\mathrm{wt} \%$ FrxB present in maltodextrin for future unknown samples. The experiments were performed with accurately weighed samples dissolved in $\mathrm{D}_{2} \mathrm{O}$. Figures 11 and 12 show the resulting stacked plots of the ${ }^{1} \mathrm{H}$ and ${ }^{11} \mathrm{~B}$ NMR spectra, respectively, obtained on these calibration samples. Liquid-state NMR experiments were not attempted on FrxB mixed with magnesium stearate as the magnesium stearate is not soluble in water.

Figure 11 shows the correlation between ${ }^{1} \mathrm{H}$ NMR anomeric signal intensity and $w t \%$ FrxB. The ${ }^{1} \mathrm{H}$ NMR calibration was obtained by normalization of the ${ }^{1} \mathrm{H}$ NMR spectra to an equal total area across the entire spectrum. This allowed observation of a decrease in the anomeric proton signal intensity of maltodextrin (peak at $5.38 \mathrm{ppm}$ ) as the $\mathrm{wt} \%$ of FrxB in the sample increased.

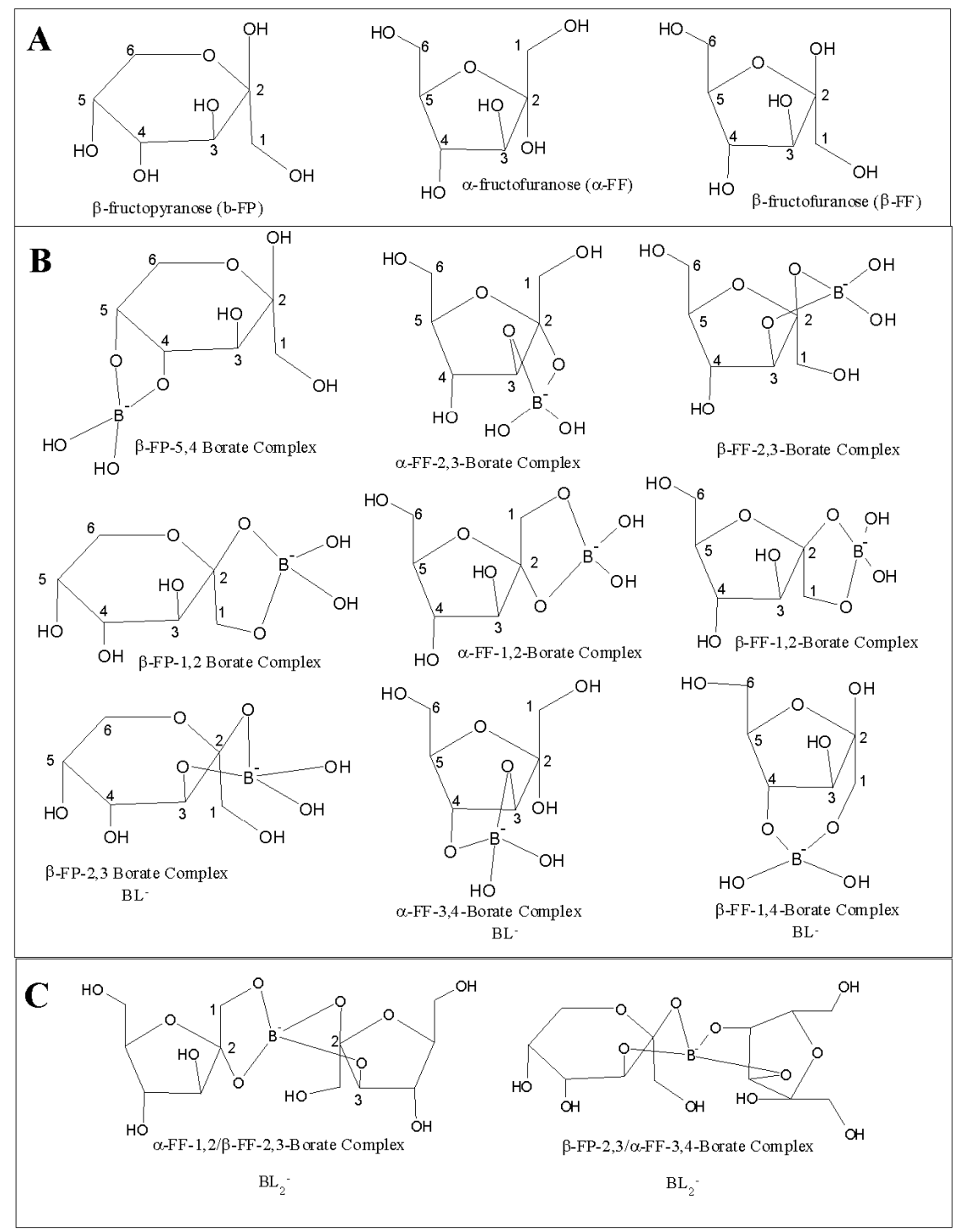

Figure 10. Probable structures of FrxB fructoborate complex. A) Predominant structures of D-fructose in water, B) Some of the potential $\mathrm{BL}^{-}$structures, C) two examples of $\mathrm{BL}_{2}^{-}$structures

The ${ }^{11} \mathrm{~B}$ calibration, shown in Figure 12, was performed in two different ways. The first approach was to use the absolute signal intensity integration across the entire spectrum. The second approach was to utilize the change in 
boron coordination chemistry that is observed as the FrxB content in maltodextrin was varied. The relative intensities of the peaks due to di-ester complex $\left(\mathrm{BL}_{2}^{-}\right)$and mono-ester complex $\left(\mathrm{BL}^{-}\right)$were observed to change. The mono-ester peak was observed to split into 2 resolved peaks due to threo and erythro isomers of the mono-ester. As the FrxB was diluted by maltodextrin it was observed that the di-ester converted to mono-ester. Our hypothesis for this is that, when in the presence of abundant unreacted maltodextrin hydroxyls, the di-ester borate changes coordination chemistry by releasing fructose and reacting with the maltodextrin hydroxyls to form the mono-ester. An excellent calibration was obtained from this variation in FrxB complex ratio with maltodextrin adulteration. The linear equation describing the relationship was found to be:

$$
\mathrm{y}=0.0505 \mathrm{x}+0.6394
$$

where $\mathrm{y}=\mathrm{Wt} \%$ FrxB in Maltodextrin, $\mathrm{x}=$ Ratio of mono-complex $/$ di-complex $\left(\mathrm{R}^{2}=0.9971\right)$

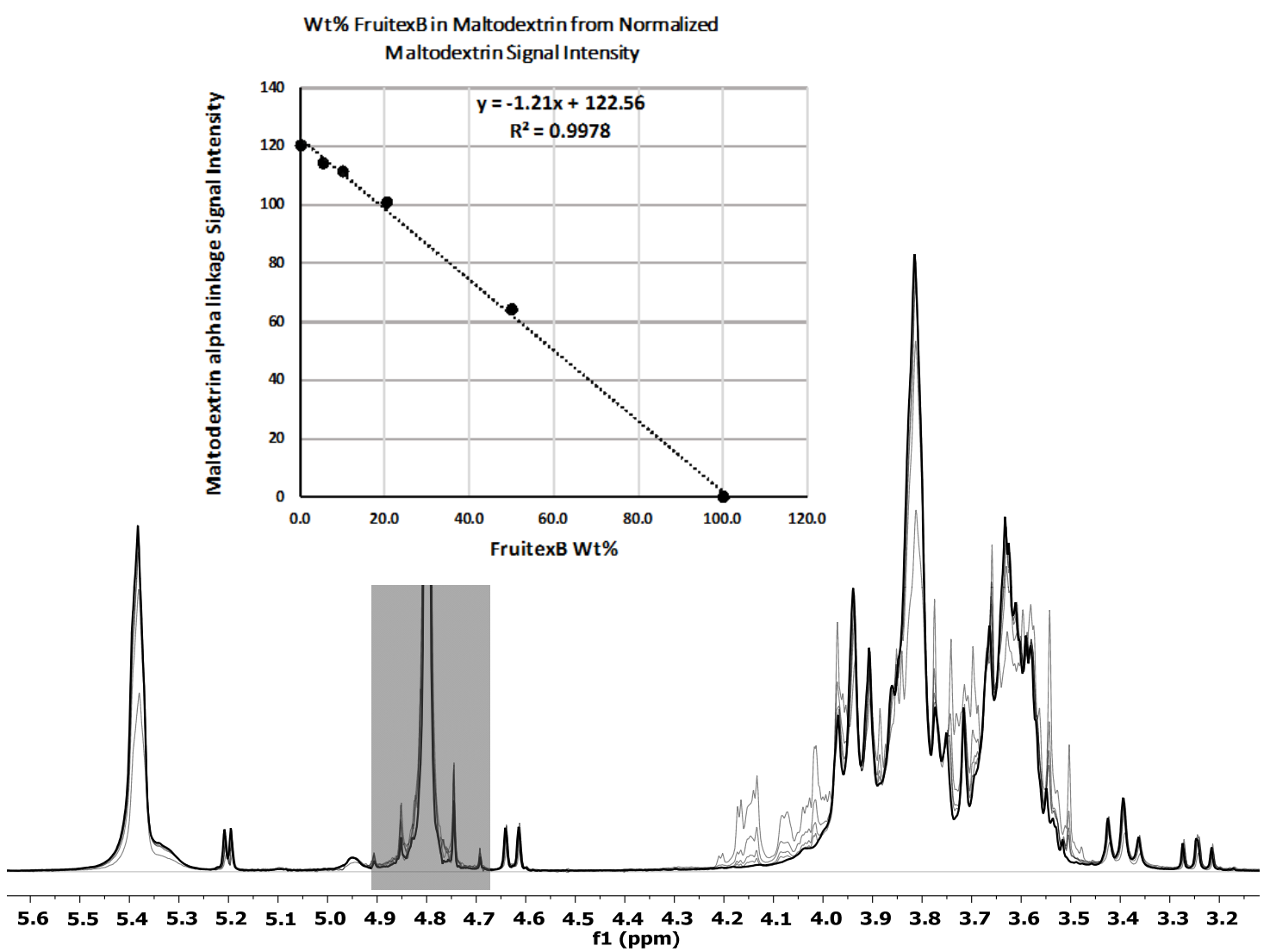

Figure 11. Superposition of liquid-state ${ }^{1} \mathrm{H}$ NMR obtained on samples of maltodextrin containing $0,5,10,20$ and $50 \mathrm{wt} \%$ FrxB. Also shown is the NMR calibration of FrxB in maltodextrin based on the variation in the maltodextrin anomeric proton signal intensity at $5.4 \mathrm{ppm}$ 


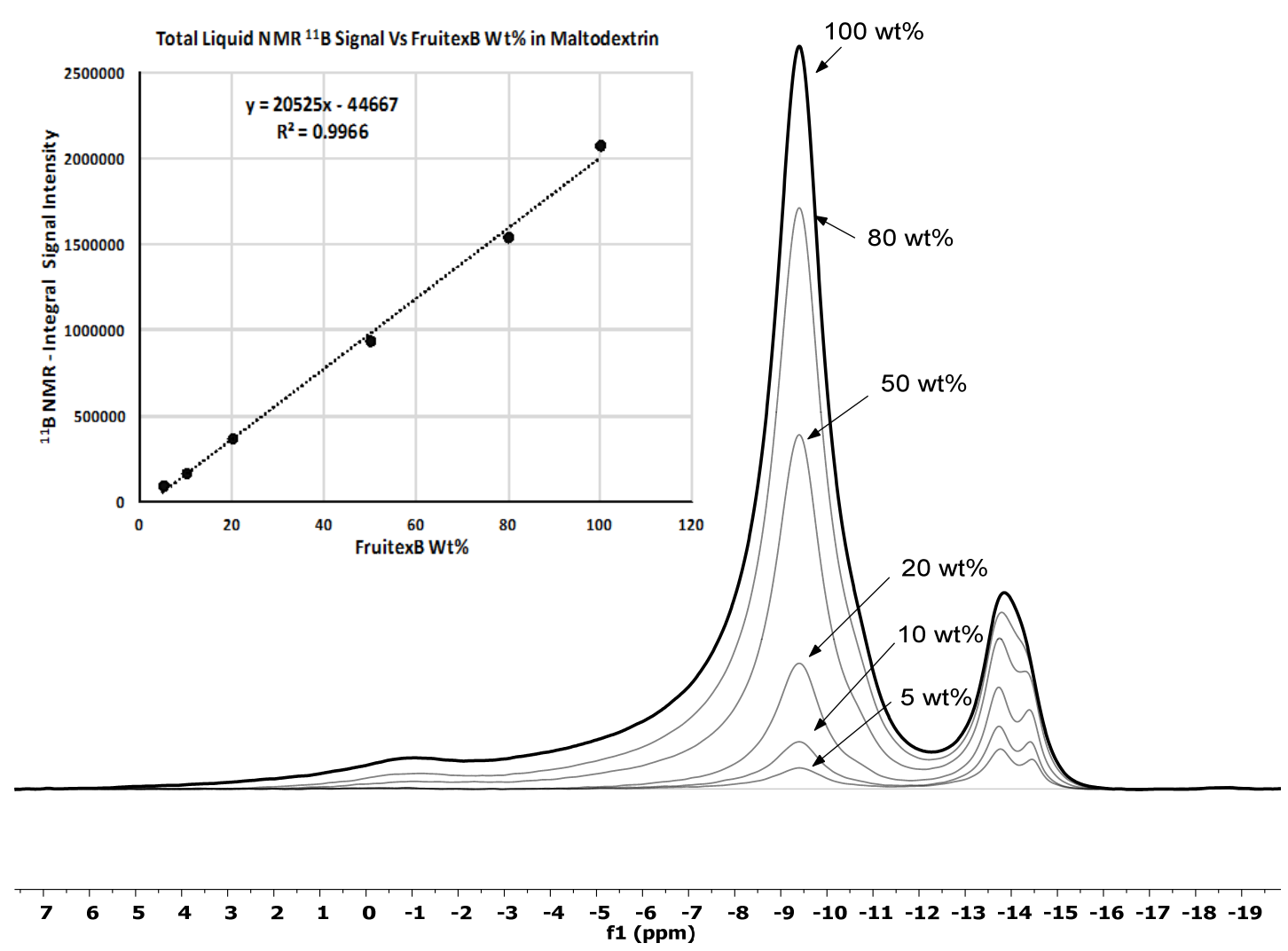

Figure 12. Liquid-state ${ }^{11} \mathrm{~B}$ NMR spectra and calibration of maltodextrin mixed with $0,5,10,20,50,80$, and 100 wt $\%$ FrxB

Solid-state ${ }^{13} \mathrm{C}$ CP-MAS NMR was also utilized to obtain quantitative calibrations of the FrxB content in both maltodextrin and magnesium stearate. Figures 13 and 14 show the superimposed calibration spectra and the correlation of FrxB content with weight adjusted total signal intensity in samples of FrxB mixed with magnesium stearate and maltodextrin, respectively. 

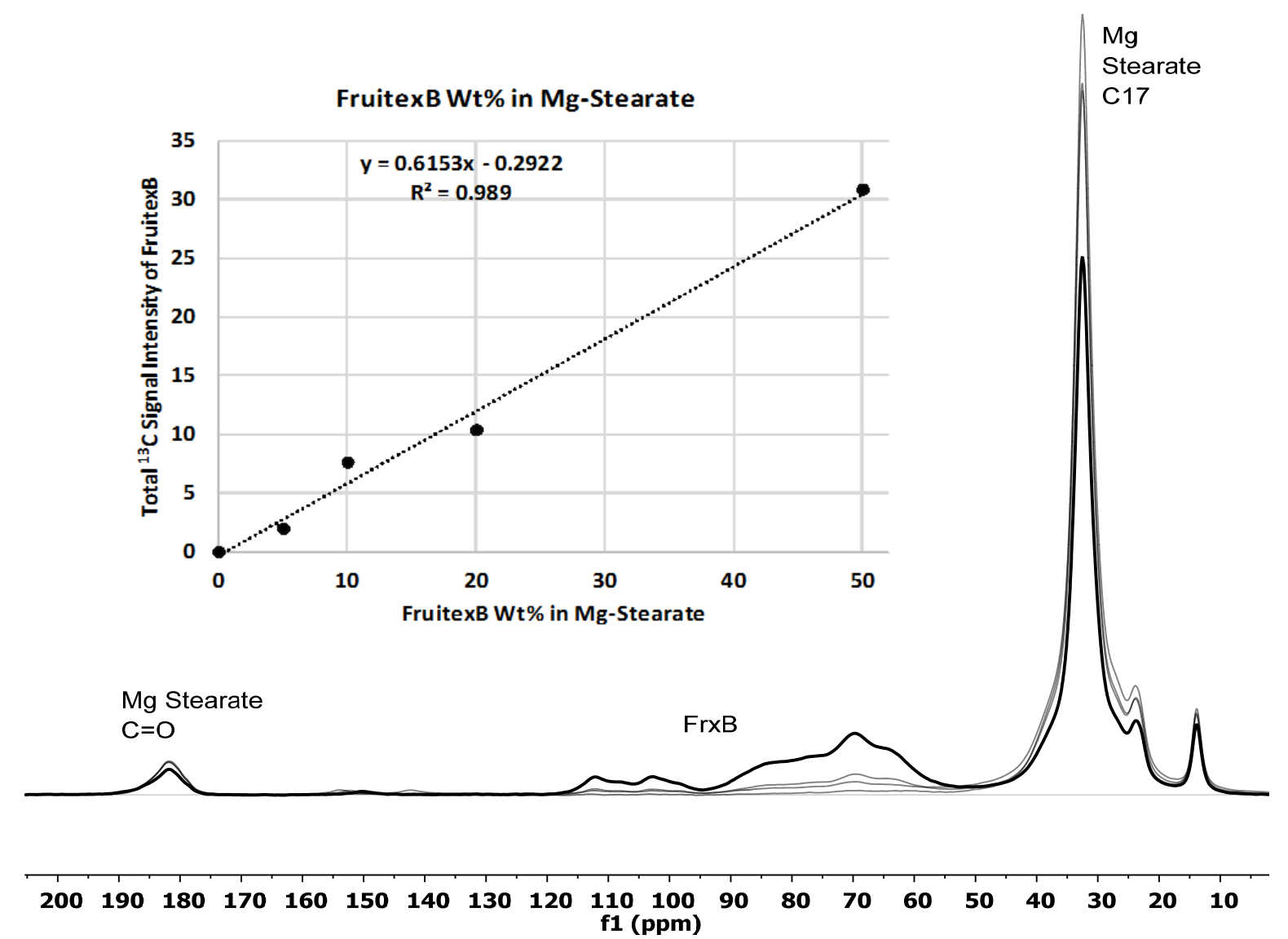

Figure 13. Solid-state ${ }^{13} \mathrm{C}$ CP-MAS NMR calibration of FrxB content in magnesium stearate

The calibrations were obtained by normalizing the total area of the spectra and then integrating those areas of the spectrum that were uniquely assignable to the FrxB component. The integrated areas were then adjusted for the sample weight present in the NMR rotor. In the magnesium stearate/FrxB mixture the entire spectral region containing the FrxB spectrum $(55-120 \mathrm{ppm})$ is in a unique area with no overlap with the magnesium stearate carbon signals. In the maltodextrin/FrxB mixtures the unique area of FrxB observation was 110-120 ppm.

Solid-state ${ }^{11} \mathrm{~B}$ MAS NMR spectra were utilized to create calibrations of FrxB content versus weight adjusted ${ }^{11} \mathrm{~B}$ NMR signal intensity for FrxB mixed with maltodextrin and magnesium stearate. The spectra of the calibration standards and the calculated correlations for FrxB in maltodextrin and magnesium stearate are shown in Figures, 15 and 16 , respectively. 


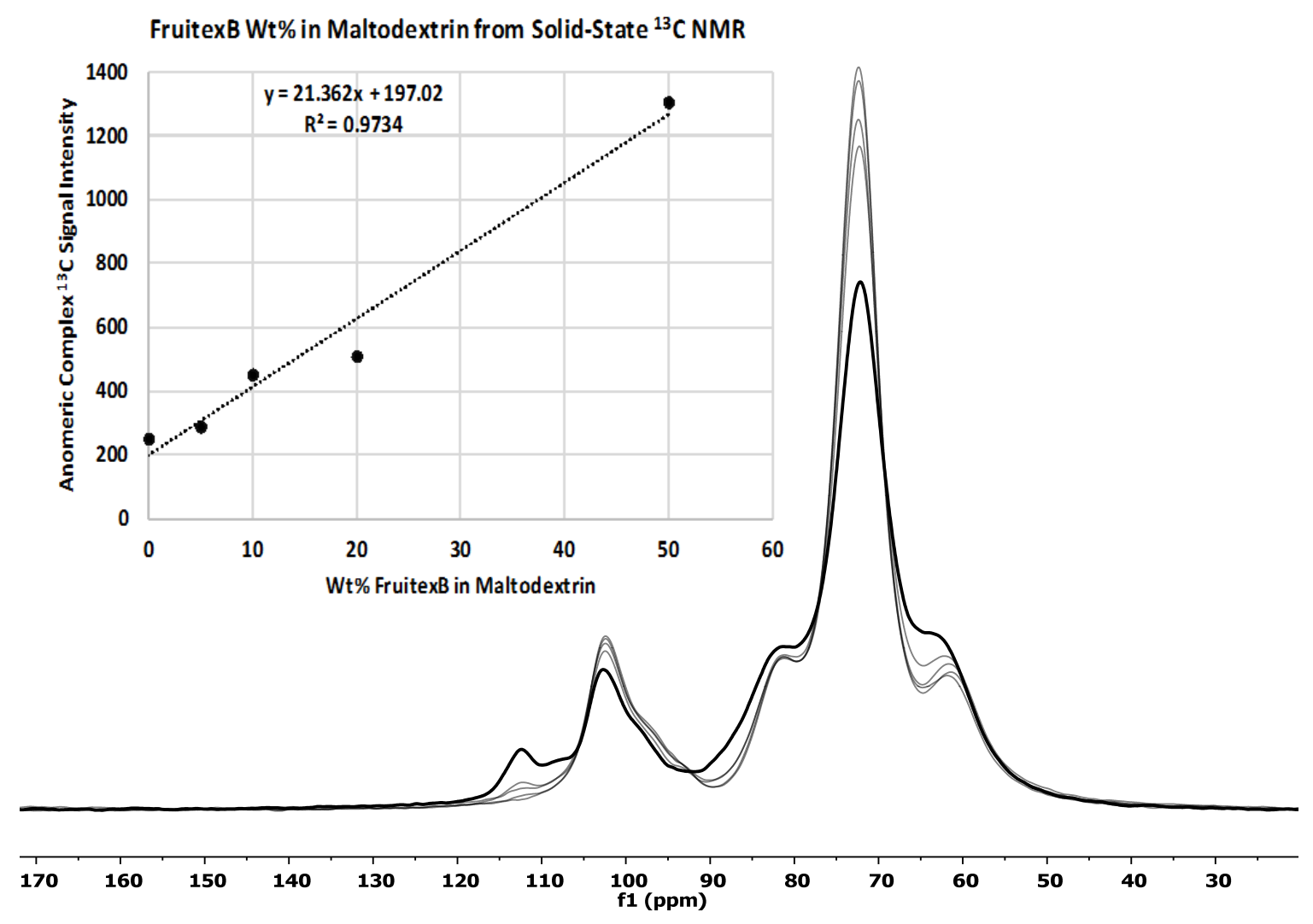

Figure 14. Solid-state ${ }^{13} \mathrm{C}$ CP-MAS NMR calibration of FrxB in maltodextrin

${ }^{11} \mathrm{~B}$ MAS NMR is the most appropriate way of obtaining a calibration due to the fact that the results are obtained without other spectral interferences since the boron observed is unique to the FrxB product. 


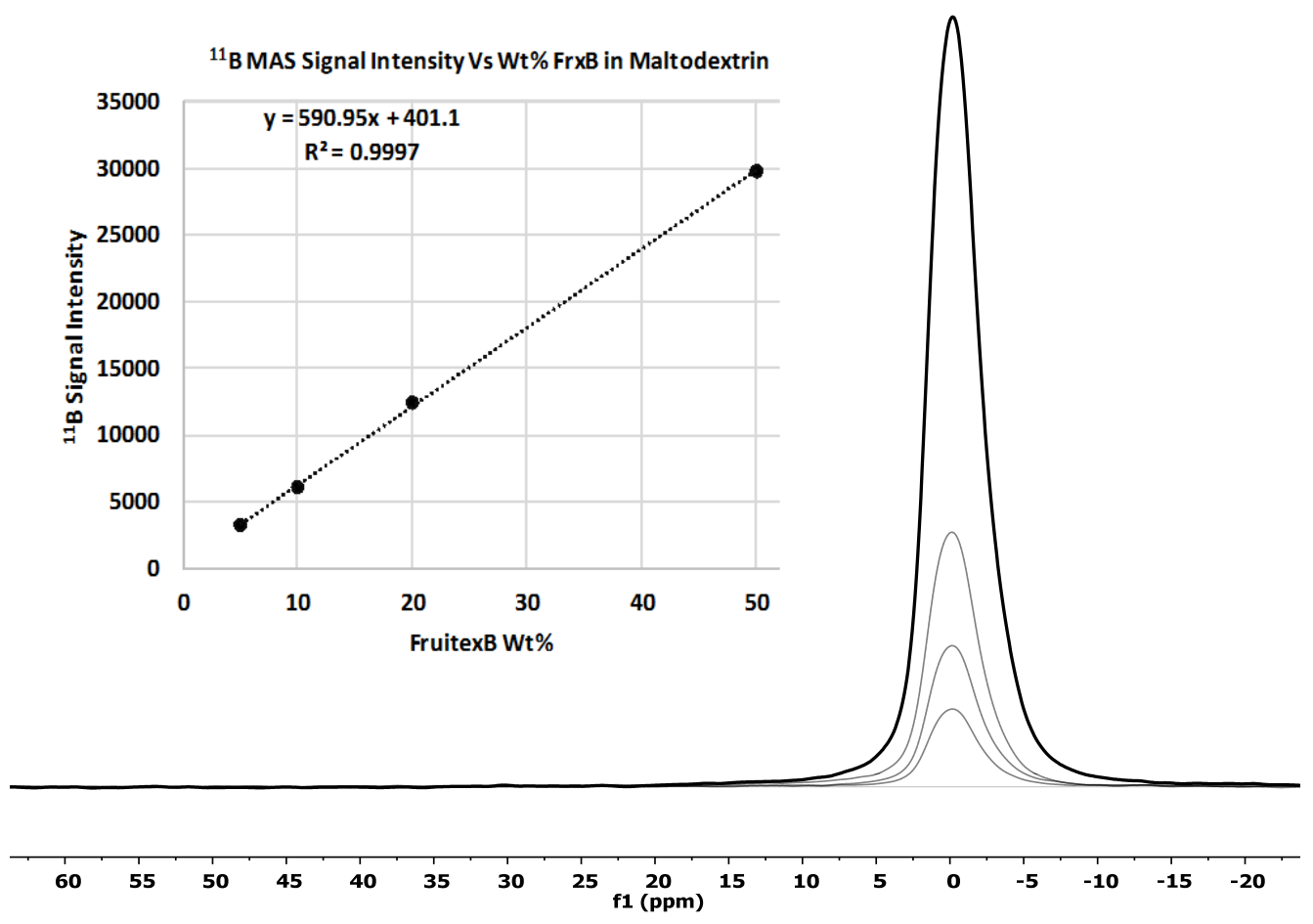

Figure 15. Solid-state ${ }^{11}$ B MAS NMR calibration of FrxB in maltodextrin

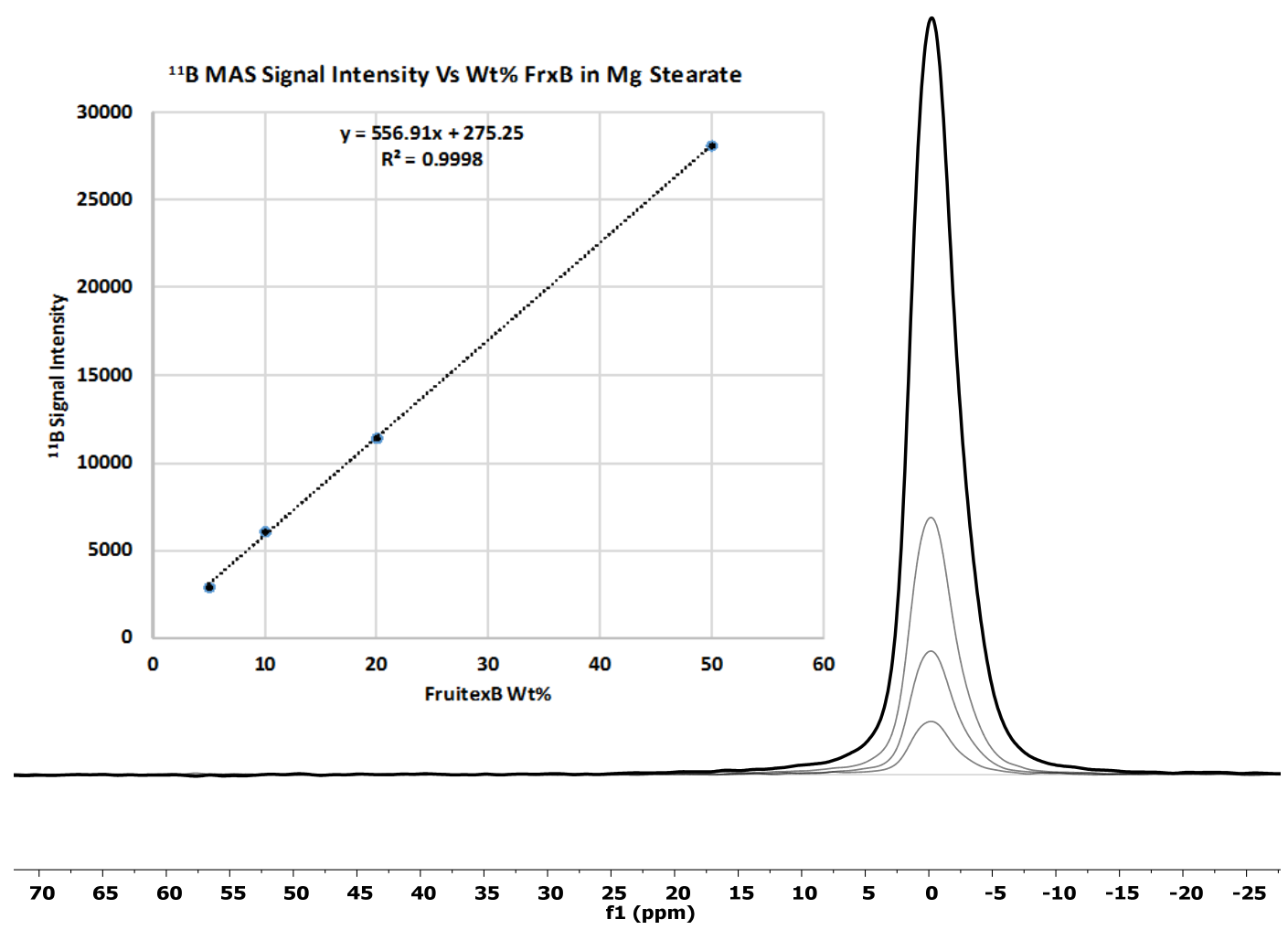

Figure 16. Solid-state ${ }^{11}$ B MAS NMR calibration of FrxB in magnesium stearate 


\section{Conclusion}

Liquid- and solid-state ${ }^{1} \mathrm{H},{ }^{13} \mathrm{C}$, and ${ }^{11} \mathrm{~B}$ NMR are excellent techniques to observe detailed chemical structure information such as the ratio of di- and mono esters, free and chelated boron distribution in the FrxB complex. During this study, no differences in chemical or physical properties were observed in liquid and solid-state NMR spectra of FrxB samples while undergoing heat stability testing. These data indicate that the samples were stable under the test temperature range of 35 to $70{ }^{\circ} \mathrm{C}$ and during heat exposure times of 2 to 18 hours. Reliable quantitative NMR spectral correlations between FrxB in various adulterant material matrices or blends with carriers or other functional ingredients can be readily obtained by direct integration measurements of liquid-state ${ }^{1} \mathrm{H},{ }^{13} \mathrm{C},{ }^{11} \mathrm{~B}$ NMR experiments, as well as from ${ }^{11} \mathrm{~B}$ and ${ }^{13} \mathrm{C}$ solid-state NMR experiments. Consequently, the reported results show that NMR technology is a very powerful method for identity, quantitative analysis and stability studies on calcium fructoborate, and can be effectively used for deeper research into borate chemistry, product standardization and industrial quality control. Due to its substantial ability to quantify amounts of FrxB within ingredient blends containing other materials, NMR can be a useful tool for assurance of consistent FrxB dosage levels and for regulatory-compliant product labeling requirements. Ultimately, after further optimization, NMR can be used for possible detection and measurement of calcium fructoborate in biological systems and fluids.

\section{Acknowledgements}

Herewith we thank Brad Evers (FutureCeuticals, Inc.) for review and helpful discussion during editing of this manuscript and Jing Yuan Wang (FutureCeuticals, Inc.) for her technical assistance at manuscript preparation.

\section{Reference}

Bakirdere, S., Örenay, S., \& Korkmaz, M. (2010). Effect of boron on human health. The Open Mineral Processing Journal, 3, 54-59.

Barclay, T., Ginic-Markovic, M., Johnston, M. R., Cooper, P., \& Petrovsky, N. (2012). Observation of the keto tautomer of D-Fructose in $\mathrm{D}_{2} \mathrm{O}$ using ${ }^{1} \mathrm{H}$ NMR Spectroscopy. Carbohydr. Res., 347(1), 136-141. http://dx.doi.org/10.1016/j.carres.2011.11.003

Bendel, P. (2005). Biomedical applications of ${ }^{10} \mathrm{~B}$ and ${ }^{11} \mathrm{~B}$ NMR. NMR Biomed., 19, 74-82. http://dx.doi.org/10.1002/nbm.886

Bolanos, L., Lukaszewski, K., Bonilla, I., \& Blevins, D. (2004). Why boron? Plant Physiology and Biochemistry, 42, 907-912. http://dx.doi.org/10.1016/j.plaphy.2004.11.002

Bonilla, I., Bolaños, L., \& Mateo, P. (1995). Interaction of boron and calcium in the cyanobacteria Anabaena and Synechococcus. Physiol. Plant, 94, 31-36. http://dx.doi.org/10.1111/j.1399-3054.1995.tb00780.x

Brown, P. H., \& Shelp, B. J. (1997). Boron mobility in plants. Plant Soil, 193, 85-101. http://dx.doi.org/10.1023/A:1004211925160

Brown, P. H., Bellaloui, N., Wimmer, M., Bassil, E., Ruiz, J., Hu, H., ... Romheld, V. (2002). Boron in plant biology. Plant Biology, 4, 203-223. http://dx.doi.org/10.1055/s-2002-25740

Caytan, E., Botosoa, E. P., Silvestre, V., Robins, R. J., Akoka, S., \& Remaud, G. S. (2007). Accurate Quantitative ${ }^{13} \mathrm{C}$ NMR Spectroscopy: Repeatability over Time of Site-Specific ${ }^{13} \mathrm{C}$ Isotope Ratio Determination. Anal. Chem., 79(21), 8266-8269. http://dx.doi.org/10.1021/ac070826k

Consonni, R., \& Cagliani, L. R. (2008). Geographical Characterization of Polyfloral and Acacia Honeys by Nuclear Magnetic Resonance and Chemometrics. J. Agric. Food Chem., 56, 6873-6880. http://dx.doi.org/10.1021/jf801332r

Dembitsky, V., Al Quantar, A., \& Srebnik, M. (2011). Natural and synthetic small boron-containing molecules as potential inhibitors of bacterial and fungal quorum sensing. Chemical Reviews, 111(1), 209-237. http://dx.doi.org/10.1021/cr100093b

Dinca, L., \& Scorei, R. (2013). Boron in Human Nutrition and its Regulations Use. J. Nutr. Ther., 2, 22-29. http://dx.doi.org/10.6000/1929-5634.2013.02.01.3

Freude, D. (2000). Quadrupolar nuclei in solid-state nuclear magnetic resonance. In R. A. Meyers (Ed) Encyclopedia of Analytical Chemistry (pp. 12188-12224). Wiley.

Hu, H., Penn, S. C., Lebrilla, C. B., \& Brown, P. H. (1997). Isolation and characterization of soluble boron complexes in higher plants. Plant Physiol., 113, 649-655. http://dx.doi.org/10.1104/pp.113.2.649

Hunt, C. (2012). Dietary boron: Progress in establishing essential roles in human physiology. J. Trace Elem. Exp. Med., 26, 157-160. http://dx.doi.org/10.1016/j.jtemb.2012.03.014 
Köse, D., Zümreoglu-Karan, B., Hökelek, T., \& Sahin, E. (2010). Boric acid complexes with organic biomolecules: Mono-chelate complexes with salicylic and glucuronic acids. Inorganica Chimica Acta, 363, (14), 4031-4037. http://dx.doi.org/10.1016/j.ica.2010.08.001

Köse, D., Zümreoglu-Karan, B., Hökelek, T., \& Sahin, E. (2014). Boric acid complexes with thiamine (vitamin B1) and pyridoxine (vitaminB6). Inorganica Chimica Acta, 413, 77-83. http://dx.doi.org/10.1016/j.ica.2013.12.045

Makkee, M., Keibook, A. P. G., \& van Bekkum, H. (1985). Studies on borate esters III. Borate esters of D-mannitol, D-glucitol, D-fructose, D-glucose in water. Recl. Trav. Chim. Pays-Bas, 104, 230-235. http://dx.doi.org/ 10.1002/recl.19851040905

Matsunaga, T., \& Nagata, T. (1995). In vivo ${ }^{11}$ B NMR observation of plant tissue. Anal. Sci., 11, 889-892. http://dx.doi.org/10.1007/s12011-011-8972-6

Mazzoni, V., Bradesi, P., Tomi, F., \& Casanova, J. (1997). Direct qualitative and quantitative analysis of carbohydrate mixtures using ${ }^{13} \mathrm{C}$ NMR spectroscopy: application to honey. Magn. Reson. Chem., 35, S81-90. http://dx.doi.org/10.1021/jf801332r

Meacham, S., Karakas, S., Wallace, A., \& Altun, F. (2010). Boron in human health: evidence for dietary recommendations and public policies. Open Miner. Process. J., 413, 77-83.

Miljkovic, D. (1999). US patent 5.962 .049 (issued October 5, 1999).

Nielsen, F., \& Meacham, S. (2011). Grrowing evidence for human health benefits of boron. Journal of Evidence-Based Complementary \& Alternative Medicine, 16(3), 169-180. http://dx.doi.org/10.1177/2156587211407638

Pauli, G. F., Gödecke, T., Jaki, B. U., \& Lankin, D. C. (2012). Quantitative ${ }^{1}$ H NMR. Development and Potential of an Analytical Method: An Update. J. Nat. Prod., 75(4), 834-851. http://dx.doi.org/10.1021/np200993k

Pieters, L. A., \& Vlietinck A. J. (1989). Applications of quantitative ${ }^{1} \mathrm{H}-$ and ${ }^{13} \mathrm{C}-\mathrm{NMR}$ spectroscopy in drug analysis. J. Pharm. Biomed. Anal., 7(12), 1405-1471. http://dx.doi.org/10.1016/0731-7085(89)80145-1

Reyes-Izquierdo, T., Nemzer, B., Gonzalez, A. E., Zhou, Q., Argumedo, R., Shu, C., \& Pietrzkowski, Z. (2012). Short-term intake of Calcium Fructoborate improves WOMAC and McGill scores and beneficially modulates biomarkers associated with knee osteoarthritis: A pilot clinical double-blinded placebo-controlled study. Am. J. Biomed. Sci., 4(2), 111-122. http://dx.doi.org/10.5099/aj120200111

Rotaru, P., Scorei, R., Harabor, A., \& Dumitru, M. (2010). Thermal analysis of calcium fructoborate sample. Thermochem. Acta, 506(1-2), 8-13. http://dx.doi.org/10.1016/j.tca.2010.04.006

Scorei, R., Cimpoiasu, V., \& Iordachescu, D. (2005). In vitro evaluation of antioxidant activity of calcium fructoborate. Biol. Trace Elem Res., 107, 127-134. http://dx.doi.org/10.1385/BTER:107:2:127

Scorei, R., \& Popa, R. (2010). Boron-containing compounds as preventive and chemotherapeutic agents for cancer. Anti-Cancer Agents in Medicinal Chemistry, 10(4), 346-351. http://dx.doi.org/10.2174/187152010791162289

Smith, B. M., Owens, J. L., Bowman, C. N., \& Todd, P. (1998). Thermodynamics of borate ester formation by three readily grafted carbohydrates. Carbohydr. Res., 308, 173-179. http://dx.doi.org/10.1016/S0008-6215(98)00075-5

Wagner, C. C., Ferraresi Curotto, V., Pis Diez, R., \& Baran, E. J. (2008). Experimental and Theoretical Studies of Calcium Fructoborate. Biol. Trace Elem. Res., 122, 64-72. http://dx.doi.org/10.1007/s12011-007-8060-0

Woods, W. G. (1996). Review of possible boron speciation relating to its essentiality. J. Trace Elem Exp. Med., 9 , 153-163. http://dx.doi.org/10.1002/(SICI)1520-670X(1996)9:4<153::AID-JTRA3>3.0.CO;2-S

Yamanouchi, M. (1973). The role of boron in higher plants (Part 2). The influence of boron on the formation of pectic substances. Bull. Fac. Agri Tottori Univ, XXV, 21-27.

\section{Copyrights}

Copyright for this article is retained by the author(s), with first publication rights granted to the journal.

This is an open-access article distributed under the terms and conditions of the Creative Commons Attribution license (http://creativecommons.org/licenses/by/3.0/). 